\title{
An Assessment of Association Between Macro-ergonomics Status and Employees' Prevalence of Musculoskeletal Disorders and Job Stress Outcomes in Urmia Educational and Medical Hospitals
}

\author{
Parisa Hassanzadeh $^{1(D)}$, Abolfazl Ghahramani ${ }^{2,3 *}$, Iraj Mohebbi ${ }^{4}$ (D) \\ 2. Assistant Professor of Occupational Health, Urmia University of Medical Sciences, Urmia, Iran \\ 3. Patient Safety Research Center, Urmia University of Medical Sciences, Urmia, Iran \\ 4. Social Determinants of Health Research Center, Urmia University of Medical Sciences, Urmia, Iran
}

1. Master in Ergonomics, Urmia University of Medical Sciences, Urmia, Iran

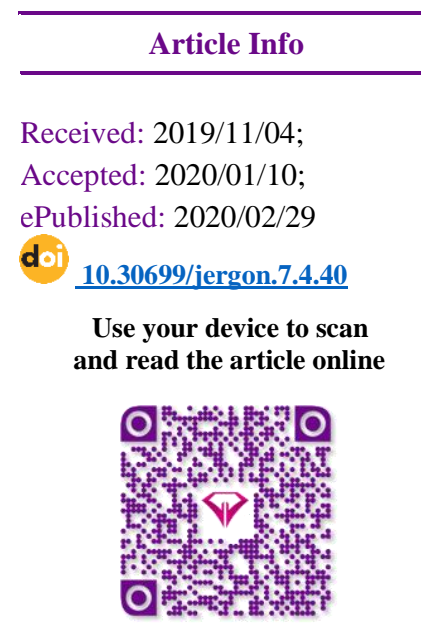

Corresponding Author Abolfazl Ghahramani Assistant Professor of Occupational Health, Urmia University of Medical Sciences, Urmia, Iran

Patient Safety Research Center, Urmia University of Medical

Sciences, Urmia, Iran

Email:

Ghahramani@umsu.ac.ir

\section{ABSTRACT}

Background and Objectives: Macro Ergonomics is a socio-technical approach that deals with organizational, and work system design, as well as the design of human-machine, human-environment, and human-job interactions. Researches show that workplace macroeconomic' conditions have undesirable effects on employees' health, and hospital staff experience high levels of occupational stress and high prevalence of musculoskeletal disorders. This study aimed to investigate the relation between macroeconomic' condition and prevalence of musculoskeletal disorders as well as outcomes of job stress among employees of hospitals affiliated to Urmia University of Medical Sciences.

Methods: This study was a descriptive cross-sectional study and 350 employees who randomly were selected from 5 hospitals participated in this study. Macroergonomic, Nordic and job stress outcomes questionnaires were used for data collection. Descriptive statistics, ANOVA and Chi-square tests were applied for data analysis.

Results: The findings of the present study indicated that out of 350 participants $217(62 \%)$ were female and 168 were nurses $(48 \%)$. Their mean age was 36.63 $( \pm 8.13)$ years and their average work experience was $11.53( \pm 7.65)$ years. The results of ANOVA test showed that the status of macro-ergonomics was significantly different in hospitals and hospital 1 had favorable condition. The majority of musculoskeletal disorder symptoms were reported in the neck $(75.7 \%)$, hip, and waist (73.7\%). The average score of job stress outcomes for the participants was lower than favorable limit. Macro-ergonomic' conditions had significant associations with musculoskeletal disorders and job stress' outcomes.

Conclusion: Based on the results of the current study, macro-ergonomic conditions had significant effects on musculoskeletal disorders and job stress outcomes. Interventional efforts should focus on organization and developing macroergonomic training programs to reduce musculoskeletal disorders and job stress and improve job conditions in hospitals.

Keywords: Macro ergonomics, Hospitals, Musculoskeletal disorders, Job stress, Macroergonomic

Copyright $\odot$ (2020, This is an original open-access article distributed under the terms of the Creative Commons Attribution-noncommercial 4.0 International License which permits copy and redistribute of the material just in noncommercial usages with proper citation.

\section{How to Cite This Article:}

Ghahramani A, Hasanzadeh P, Mohebbi I. An Assessment of Association Between Macro-ergonomics Status and Employees' Prevalence of Musculoskeletal Disorders and Job Stress Outcomes in Urmia Educational and Medical Hospitals. Iran J Ergon. 2020; 7 (4) :40-51 
بررسى ارتباط وضعيت ماكروارگونومى با شيوع اختلالات اسكلتى -عضلانى و ييامدهاى استرس شغلى در

$$
\text { بيمارستانهاى آموزشى - درمانى اروميه }
$$

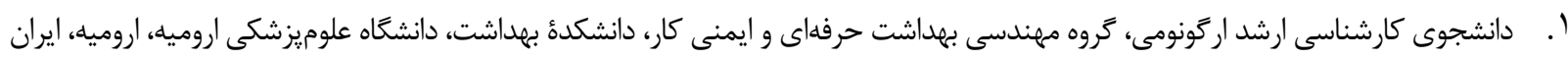

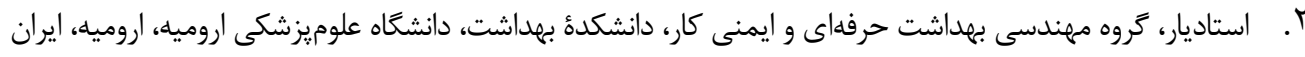

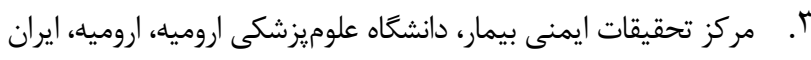

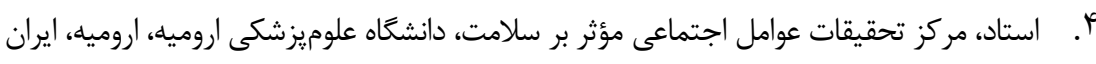

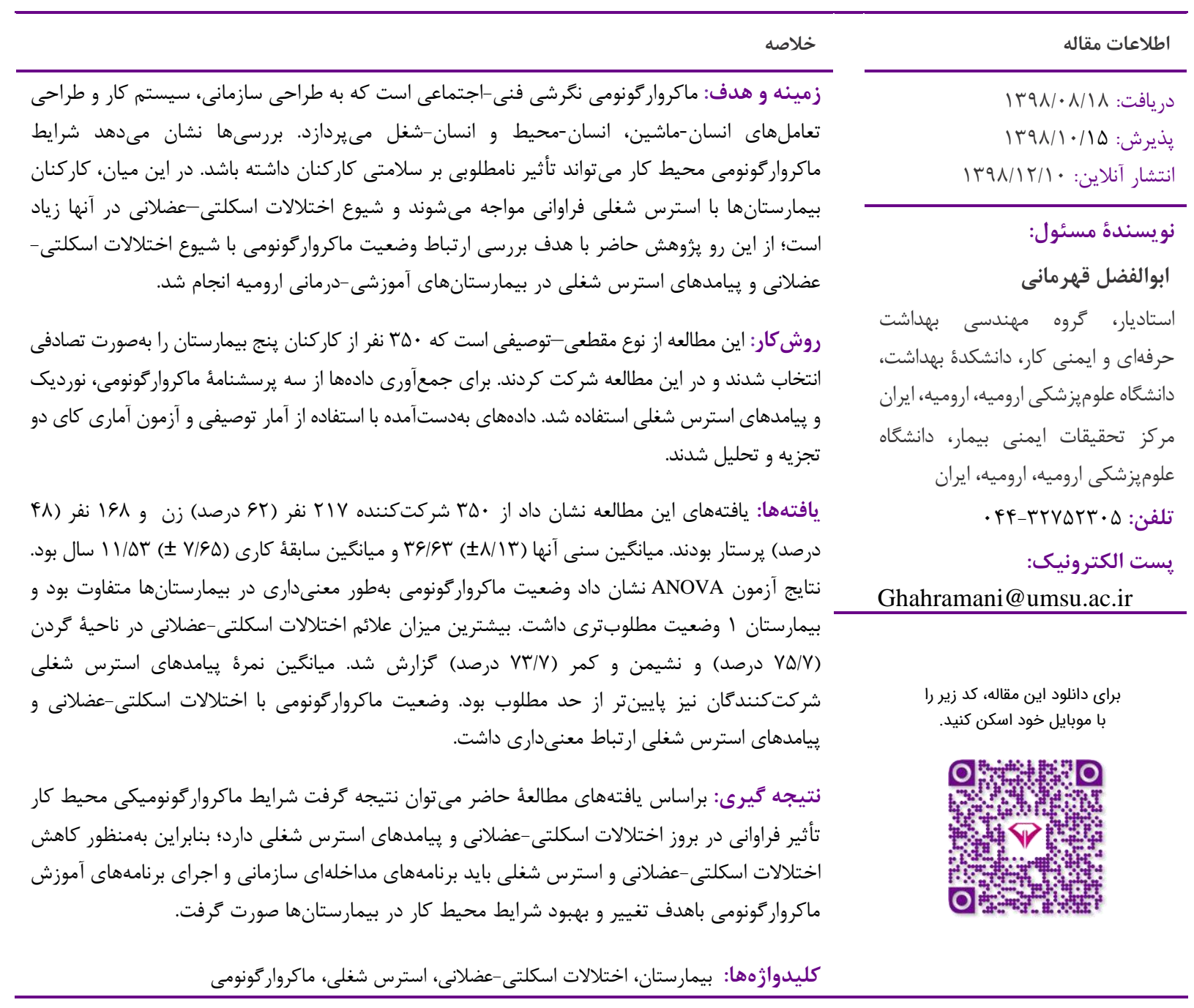

مقد مه

بروز مشكلات مربوط بهسلامتى كاركنان دارد [ع]. ماكرو-

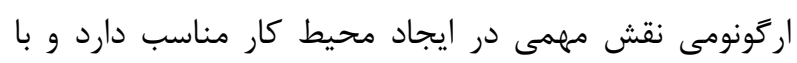

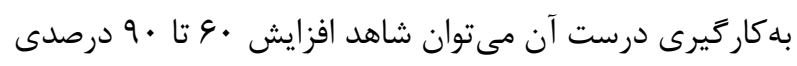

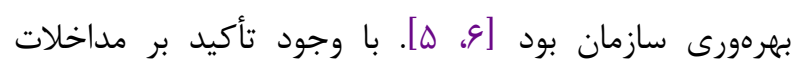
ماكروار گونومى نتايج اين مداخلات ناكافى است؛ بنابراين تحقق برد
امروزه افراد بيشتر وقت خود را در سازمانهايى سيرى مى كنند كه بهدليل وجود عوامل متعدد از جمله شرايط نامناسب خران بهداشتى و حجم كارى زياد، تأثيرات مختلفى بر سلامت افراد

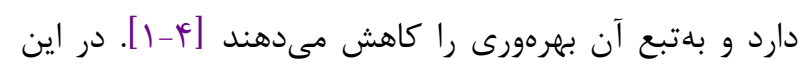

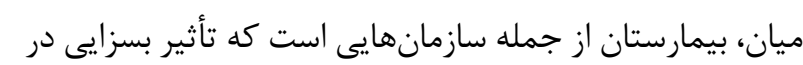




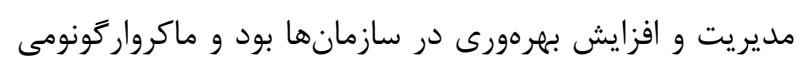

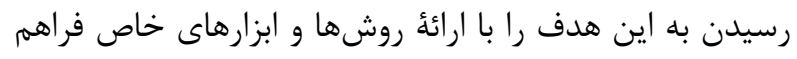

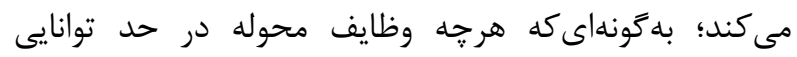

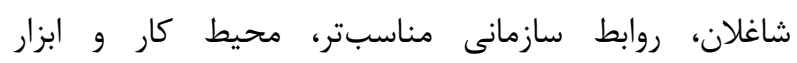

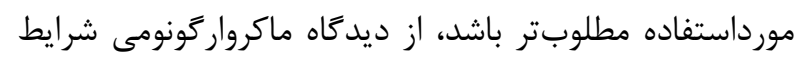

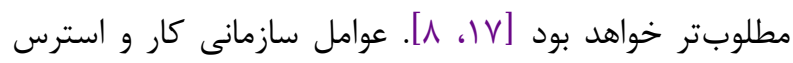
شغلى از عوامل تأثير كذار در اختلالات اسكلتى - عضلانى هستند.

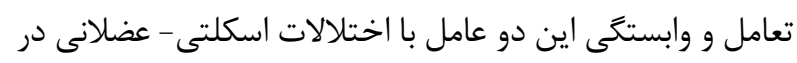

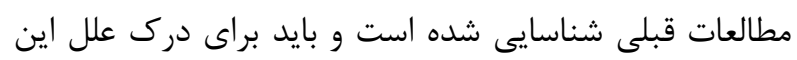

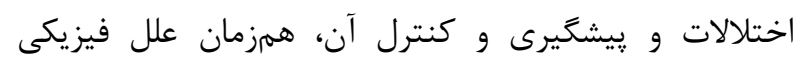

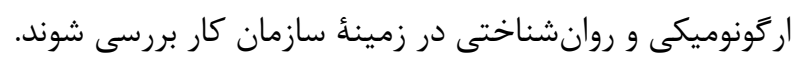

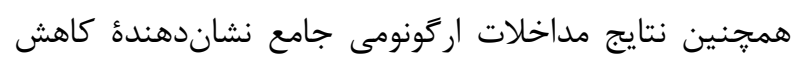

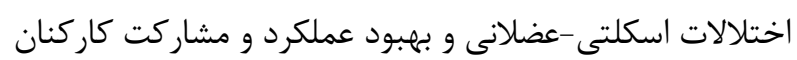

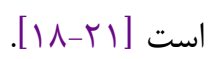

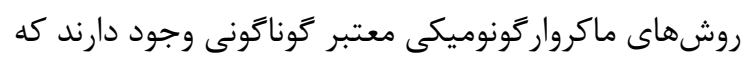

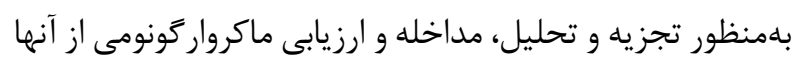

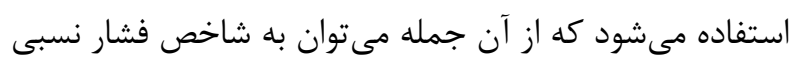
(RSI) يرسشنامة سازمانى (MOSQ)

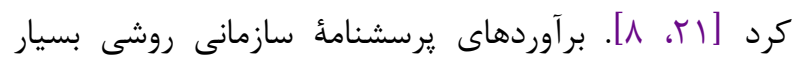

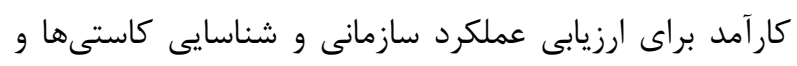

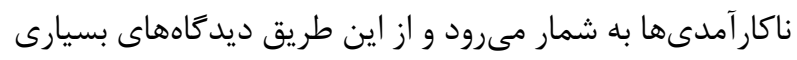

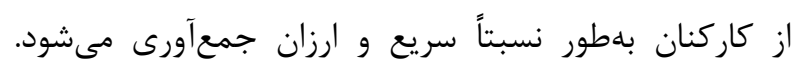

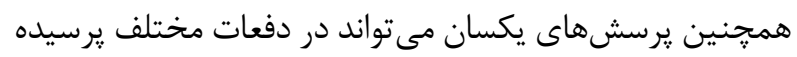

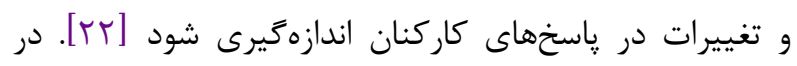
مطالعات متعددى براى بررسى وضعيت ماكرواركونومى از

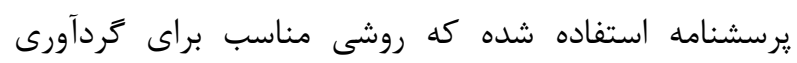

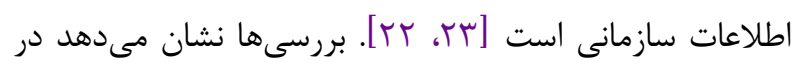

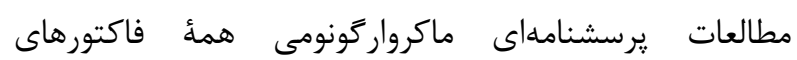

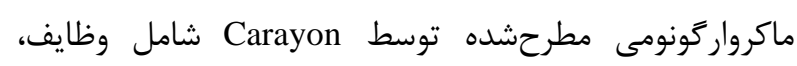

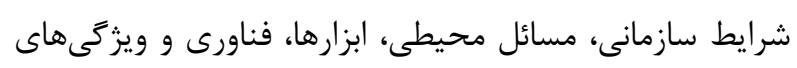

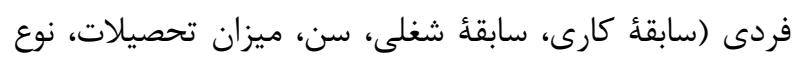

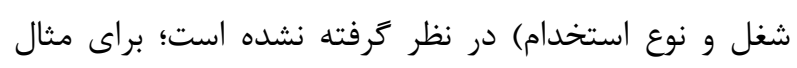
Sherehiy

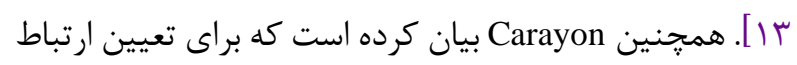
بين سازمان كار، استرس شغلى و اختلالات اسكلتى - عضلانى

\footnotetext{
${ }^{4}$ Relative Stress Index

${ }^{5}$ Macroergonomic Analysis and Design

${ }^{6}$ Macroergonomic Organizational Questionnaire Survey
}

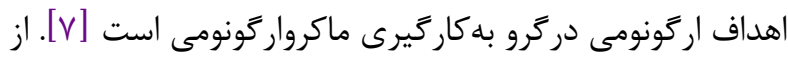

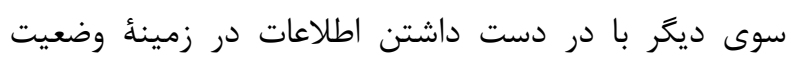

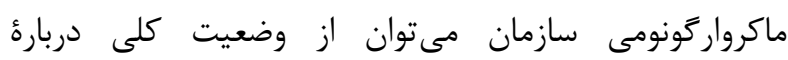

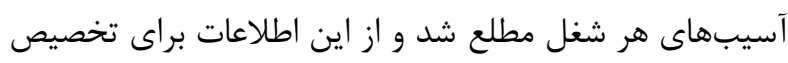

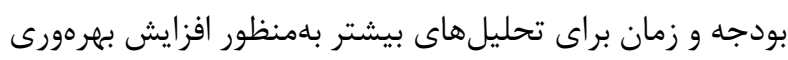

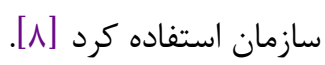
سازمانها بر سلامت كاركنان مؤثر هستند. در اين ميان،

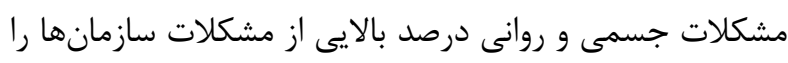

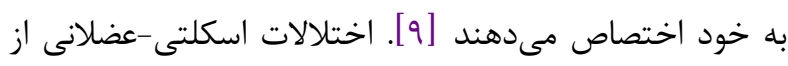

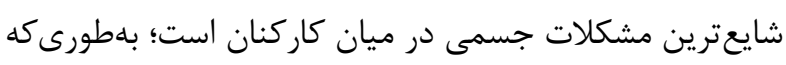

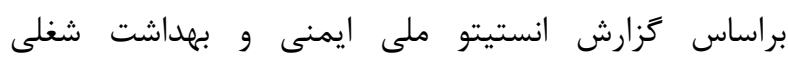

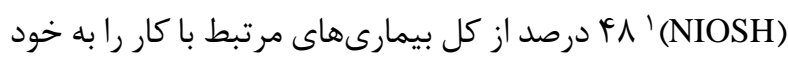

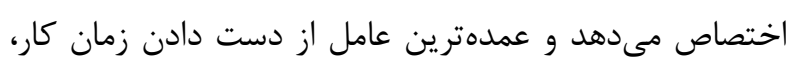

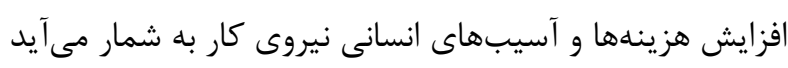

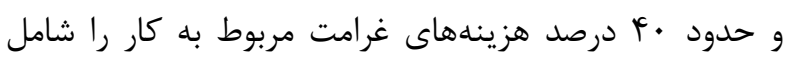

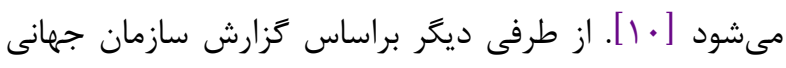

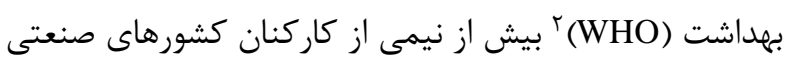

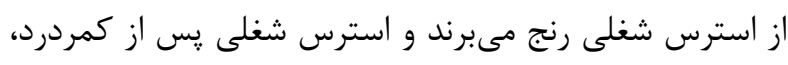

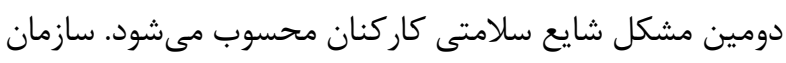

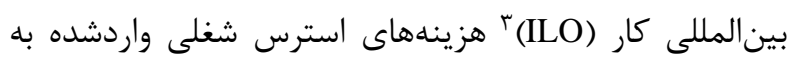

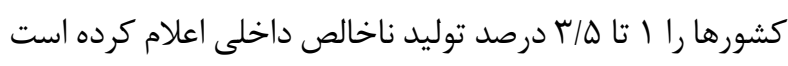

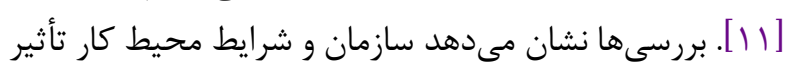

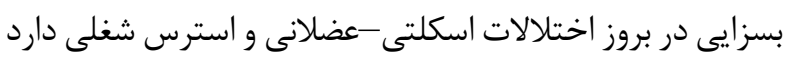

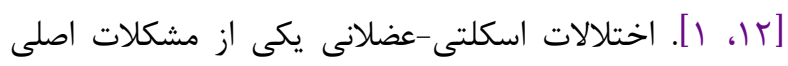

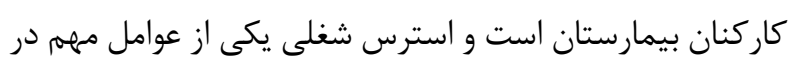

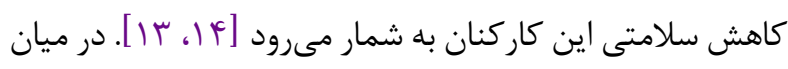

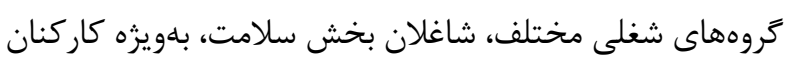

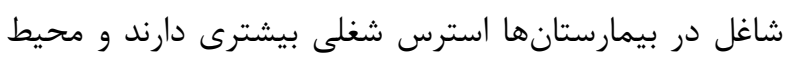

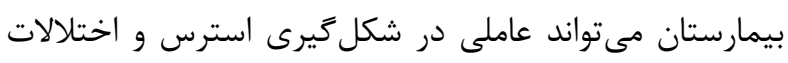

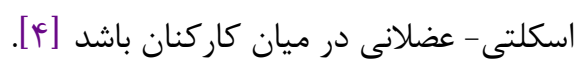

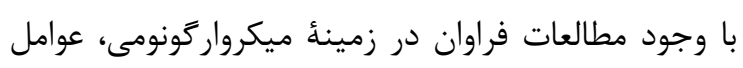

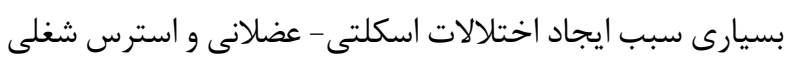

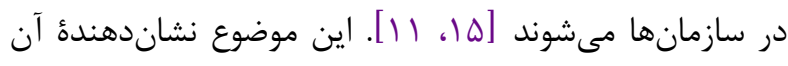

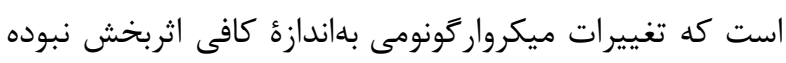

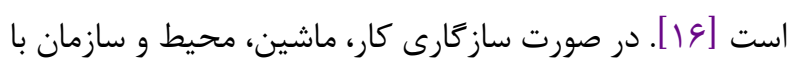

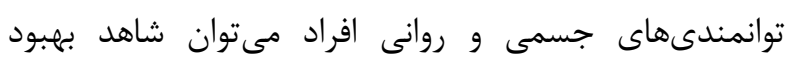

\footnotetext{
1. National Institute for Occupational Safety and Health

2. World Health Organization

3 . International Labor Organization
} 


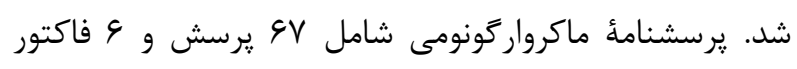

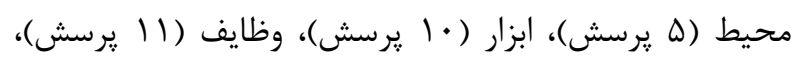

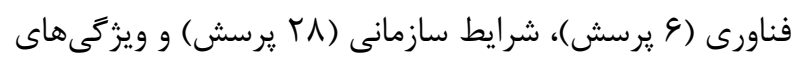

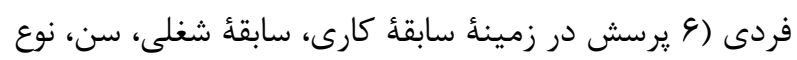

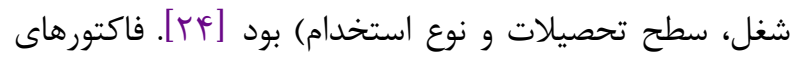

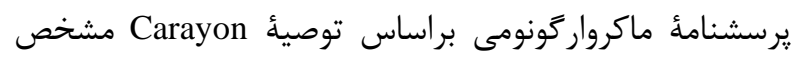

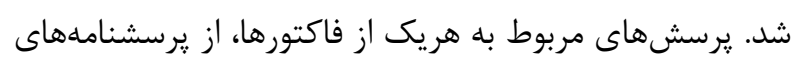
معتبر و كاربرى در مطالعات علمى قبلى دردسترس استخراج

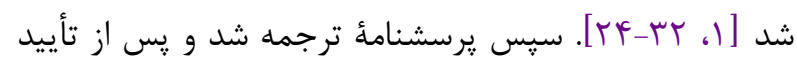
ترجمه از سوى يك متخصص، يرسشنامه در اختيار سه

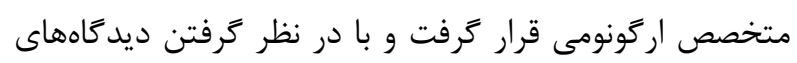

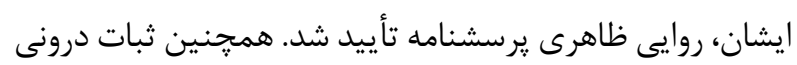

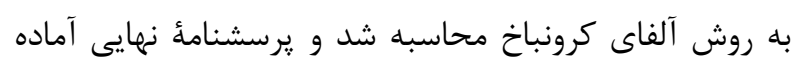
شد. ضرايب آلفاى كرونباخ در همةٔ فاكتورهاى يرسشنامه بيشتر

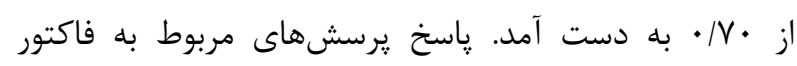

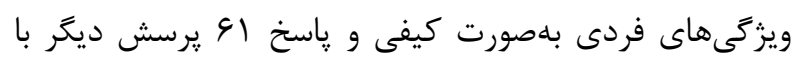

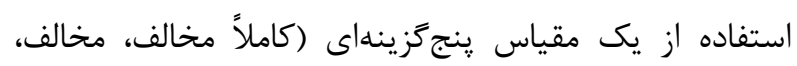

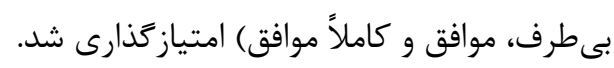

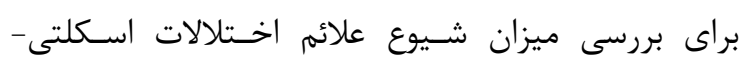

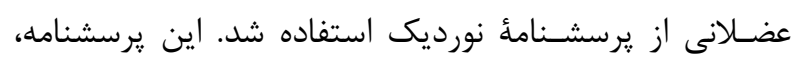

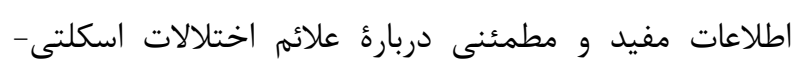

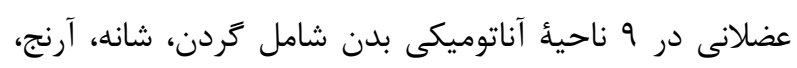

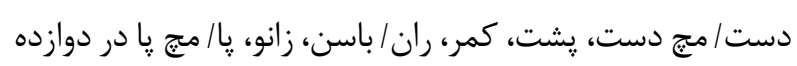

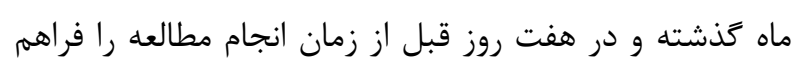

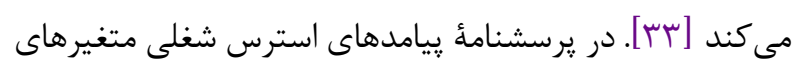
روانشناختى به علائمى مانند استرس، تضعيف روحيه، درد و

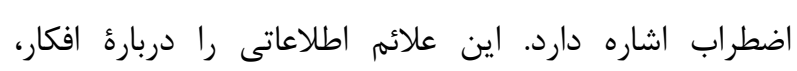

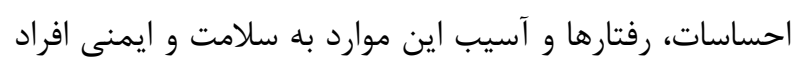
در اختيار قرار مىدهد. علائم روانى با يرسش در زمينهُ تعداد

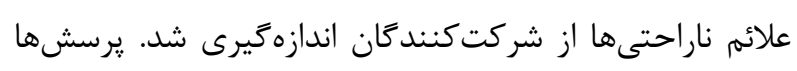
شامل مواردى بود كه فرد در اثر شرايط محيط كار از آنها رنج

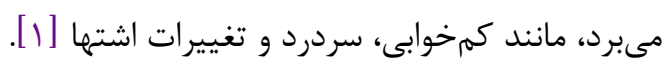

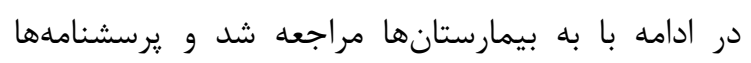

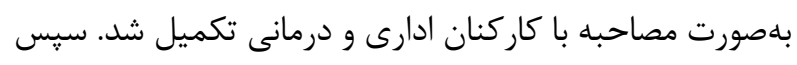
همة متغيرها كدبندى و براى تجزيه و تحليل آمارى وارد نرمافزار

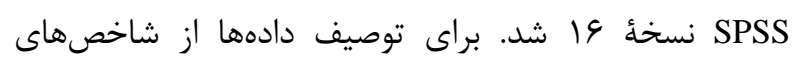
توصيفى و همجنين از جداول توزيع فراوانى استفاده شد. براى توصيف دهاى
به مطالعات علمى بيشترى نياز است [9] [1]؛ بنابراين مطالعه

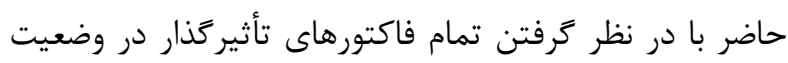
ماكروار گونومى انجام شد.

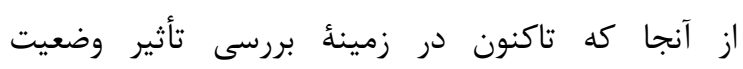
ماكروارگونومى بر سلامت كاركنان مطالعات كمترى ززارش آنده

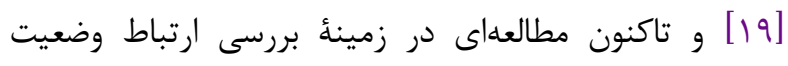

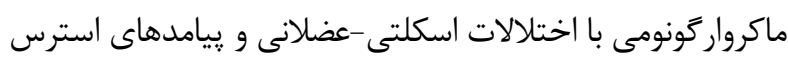
شغلى در كاركنان بيمارستانهاى كشور ما، بلويزه شهرستان

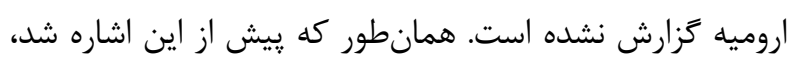

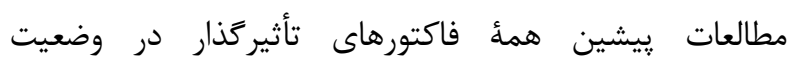
ماكروارگونومى سازمان را مدنظر قرار ندادهاند؛ بنابراين در مطالعهُ

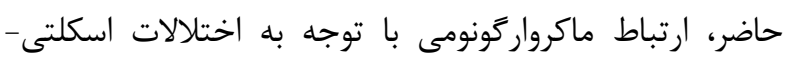
عضلانى و استرس شغلى در بيمارستانهاى آموزشى -درمانى

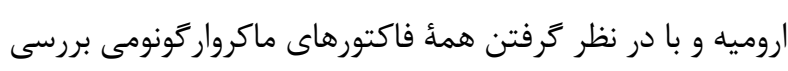

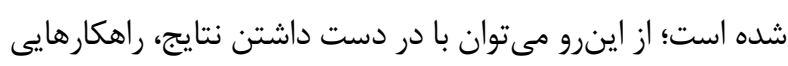

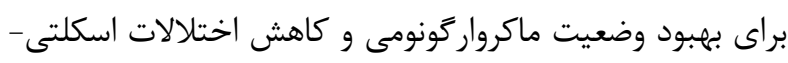
عضلانى و استرش شغلى كاركنان بيمارستانهاى آموزشى درمانى ارائه داد.

\section{مواد و روش ها - - ماد}

دادههاى اين مطالعه با استفاده از زرسشنامه و از طريق

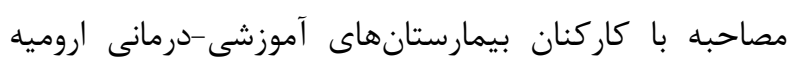

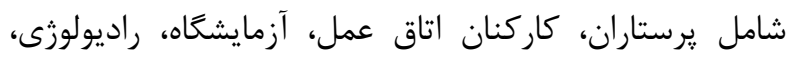
خدمات و امور ادارى جمعآورى شد. تعداد كاركنان در ينج

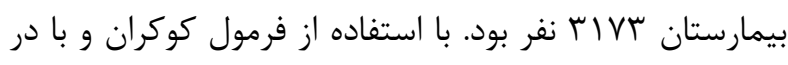

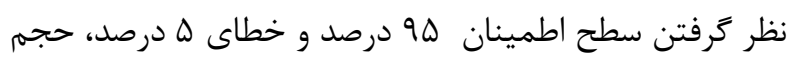
نمونه سFr نفر تعيين شد. با توجه به ملاحظات ناشى از افت إن

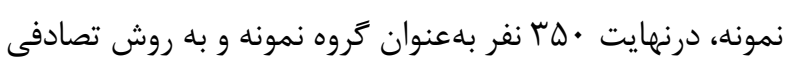

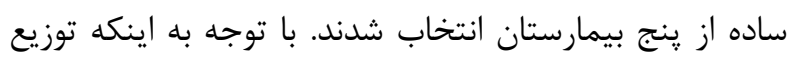
شاغلان در واحدهاى مورد مطالعه همأ بيمارستانها تقريباً

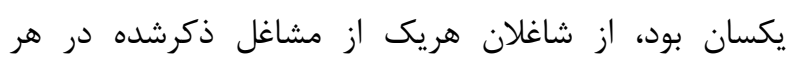
بيمارستان به تعداد مساوى نمونه خيرى شد. نمونه خيرى به به روش

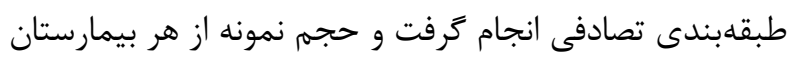
V. در اين مطالعه دادههاى موردنياز در زمينهُ بررسى ارتباط

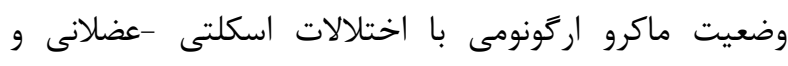

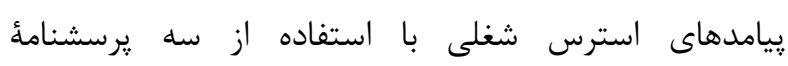

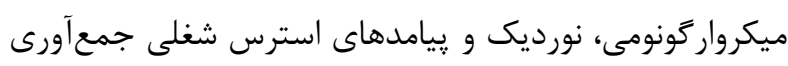


جدول ا. توزيع فراوانى مطلق و نسبى شاخصهاى توصيفى كيفى دموگرافيكى جامعهُ مورد مطالعه

\begin{tabular}{|c|c|c|c|c|c|c|c|c|}
\hline درصد & 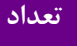 & متغير & درصد & تعداد & متغير & درصد & تعداد & متغير \\
\hline & & سن & & & سابقهُ حادثه شغلى & & & جنس \\
\hline$r V / l$ & $9 \Delta$ & $r q-r$. & 1. & $r \Delta$ & دارد & Gr & TIV & 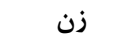 \\
\hline$r F / F$ & IKF & rq-г. & 9. & rla & ندارد & rı & rזו & مرد \\
\hline$r \cdot / 9$ & $1 \cdot 1$ & $f \cdot-f q$ & & & سابقة آموزش OHS & & & وضعيت تأهل \\
\hline \multirow[t]{2}{*}{$9 / 9$} & שו & $\Delta q-\Delta \cdot$ & $9 \cdot 19$ & rIT & دارد & v^ & TV & مجرد \\
\hline & & سابقهُ شغلى (سال) & $\mu q / 4$ & Ir人 & 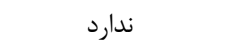 & rt & VV & متأهل \\
\hline זI/V & 111 & $\Delta-1$ & & & رده شغلى & & & تحصيلات \\
\hline $19 / 9$ & $\Delta \wedge$ & $1 \cdot-4$ & $11 / 4$ & rt & خدمات & $\cdot 19$ & r & ابتدايى \\
\hline re/q & 149 & $r \cdot-11$ & $11 / 4$ & f. & كادر ادارى & $r / r$ & $\wedge$ & راهنمايى \\
\hline \multirow[t]{2}{*}{$14 / 9$} & $\Delta T$ & $r \cdot-r l$ & $i \wedge$ & 191 & 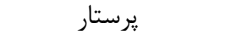 & f & if & دبيرستان \\
\hline & & سابقهُ كار (سال) & $\Delta / V$ & r. & راديولوزى & $94 / 1$ & TrG & دانشخاهى \\
\hline זוV & 111 & $\Delta-1$ & $11 / 4$ & f. & اتاق عمل & & & شيفت كارى \\
\hline $19 / \pi$ & $\Delta V$ & $1 \cdot-9$ & $\mid f / r$ & $\Delta \cdot$ & علوم آزمايشگاهى & $\Delta r / q$ & $1 \wedge \Delta$ & صبح \\
\hline re/q & 119 & $r \cdot-11$ & & & & $19 / 1$ & GV & عصر \\
\hline $10 / 1$ & $\Delta r$ & $r \cdot-r)$ & & & & r & 91 & شب \\
\hline
\end{tabular}

بهداشت حرفهاى و تنها ض؟ نفر ( • ( درصد) سابقؤ داشتن حادثه

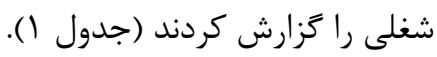

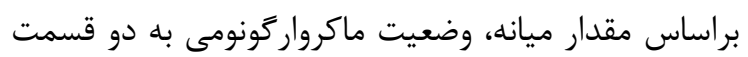

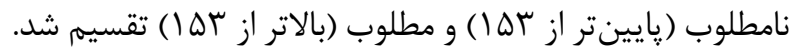

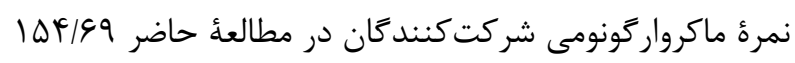

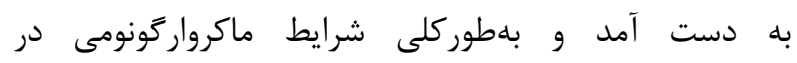

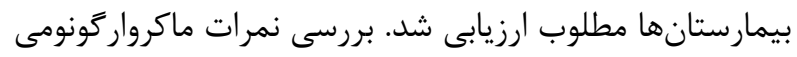

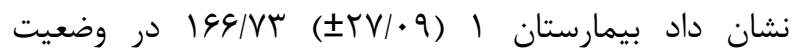

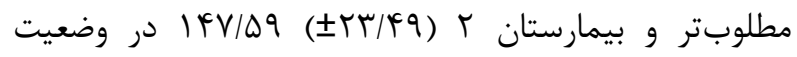

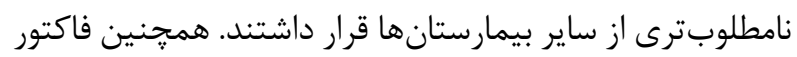

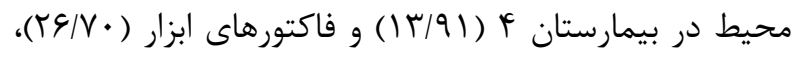

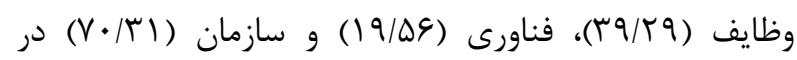

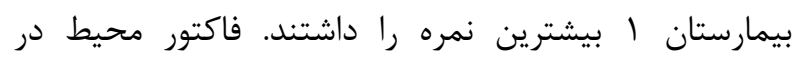

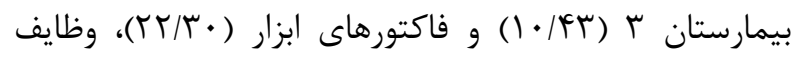

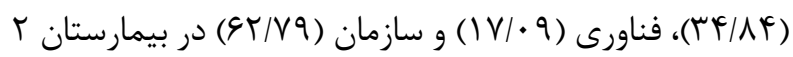

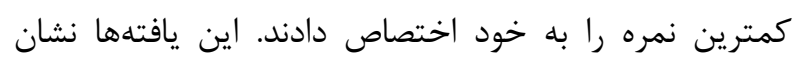

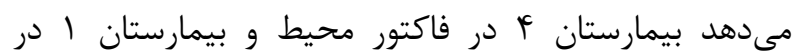
فاكتورهاى ابزار، وظايف، فناورى و سازمان مطلوبتر بودند.
بررسى رابطه ماكروارگونومى با اختلالات اسكلتى-عضلانى و ييامدهاى استرس شغلى از آزمون كاىدو استفاده شد.

يافته ها

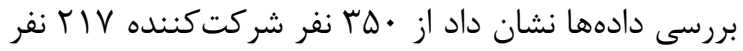

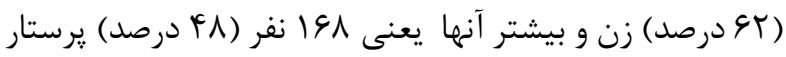

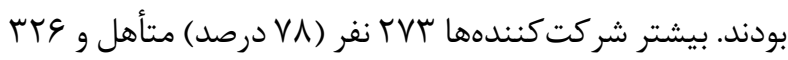

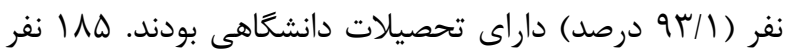

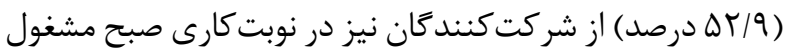

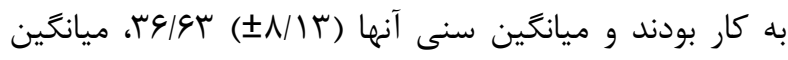

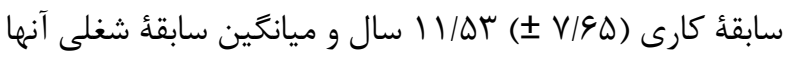

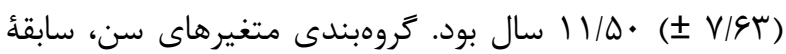
كار و سابقه شغلى نشان مىدهد محدودة سنى سنى بيشتر

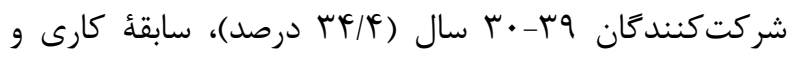

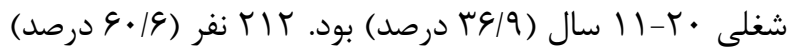
از شركت كنندكان سابقُ شركت در دورههاى آموزشى ايمنى و 
بالا (نمرة بيشتر از \&) تقسيمبندى شدند [1]

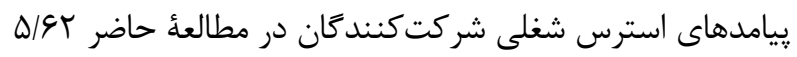

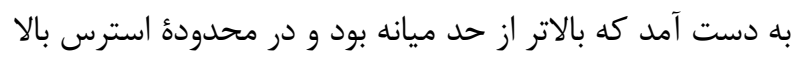

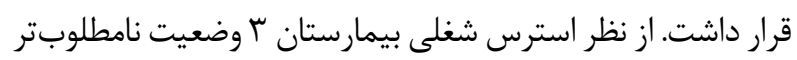

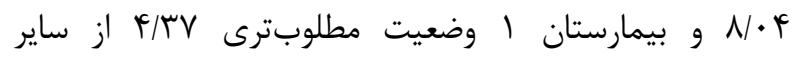

$$
\text { بيمارستان ها داشت. }
$$

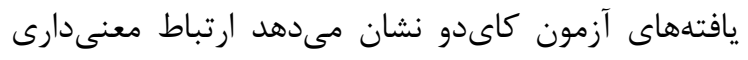

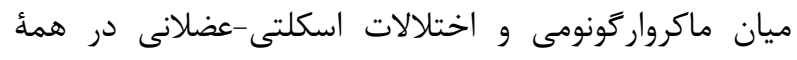

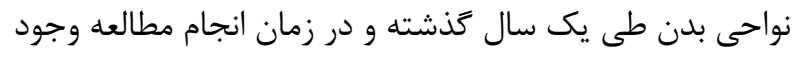

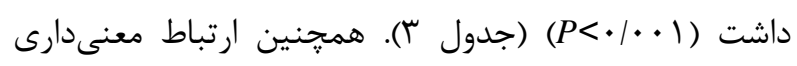

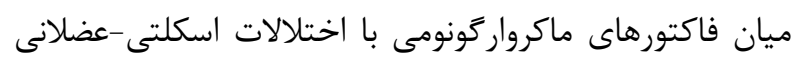

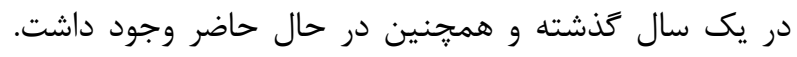

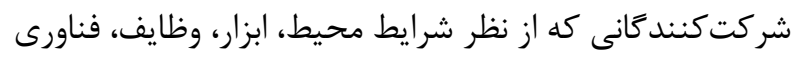

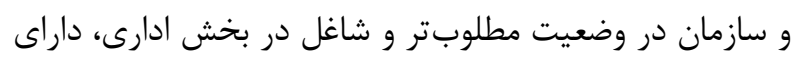

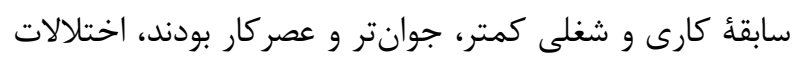

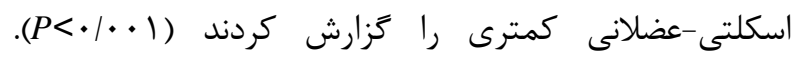

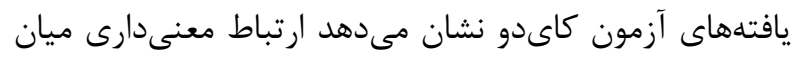

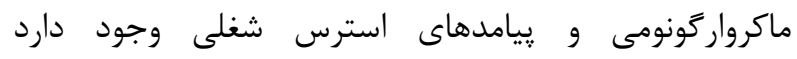

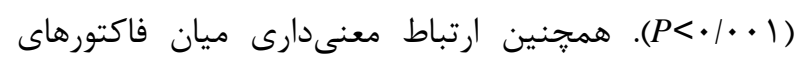

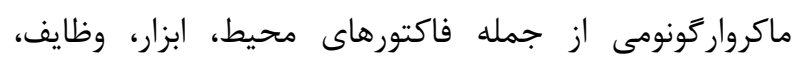

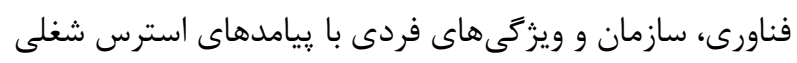

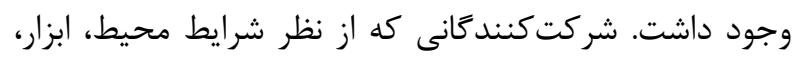

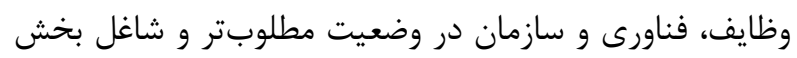

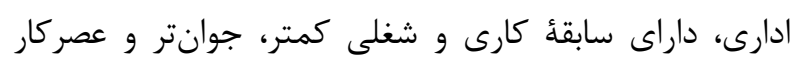

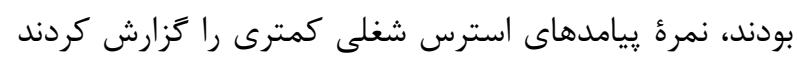

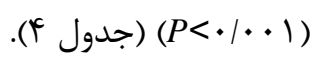

بيمارستان ץ نيز در فاكتور محيط و بيمارستان r د در ساير

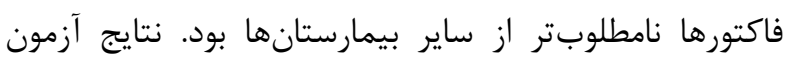

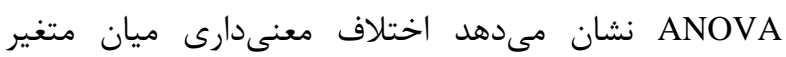

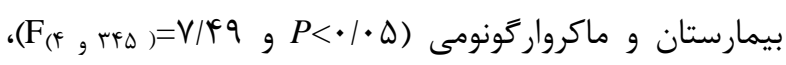

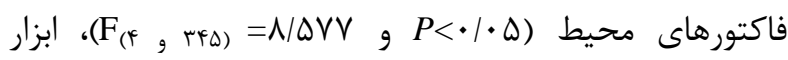

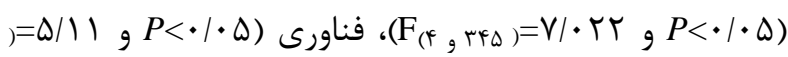
(F)

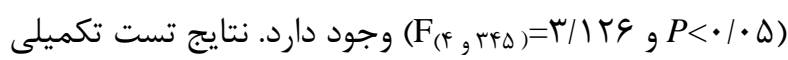

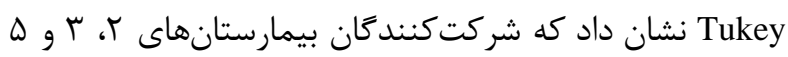

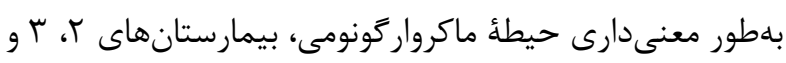

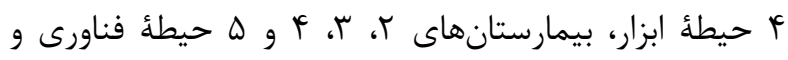

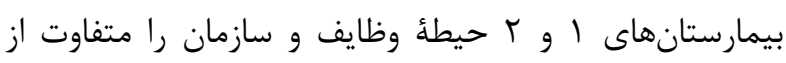

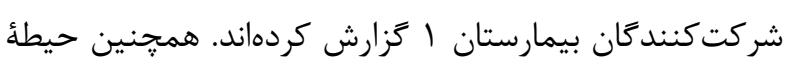

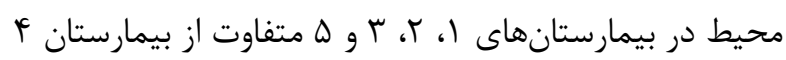
كزارش شده است (جدول ب r). تعداد و درصد شيوع اختلالات اسكلتى -عضلانى در دوازده ماه كذشته در شركت شنند

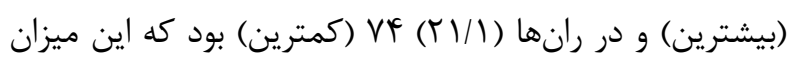

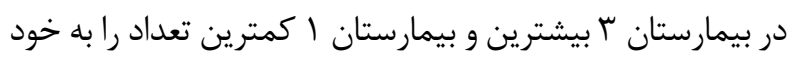

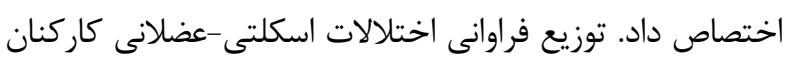

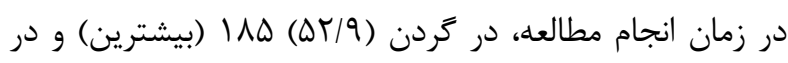

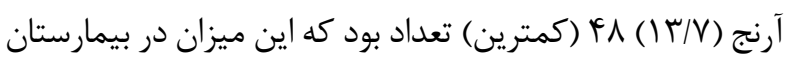

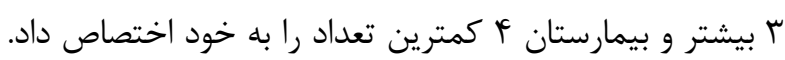

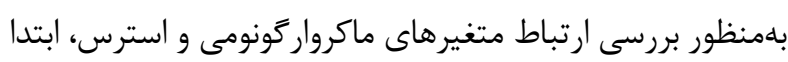

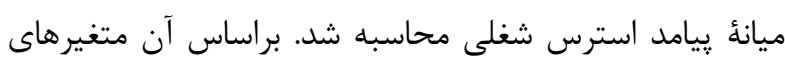

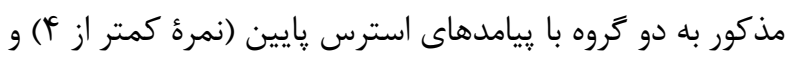

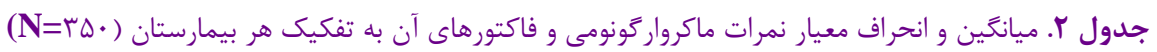

\begin{tabular}{|c|c|c|c|c|c|c|c|c|}
\hline$P$ & $\mathbf{F}$ & كل - ال & $\Delta$ & f & r & r & 1 & باكتورهارستان \\
\hline \multirow{2}{*}{$\cdot 1 \cdot \cdot 1$} & \multirow{2}{*}{$V / F q$} & $( \pm Y Y / \varepsilon /)$ & $( \pm Y G / F T)$ & $( \pm r r / \wedge 9)$ & $( \pm \mid \varepsilon / T r)$ & $( \pm r r / r q)$ & $( \pm r V / \cdot q)$ & \multirow{2}{*}{ ماكروارگونومى } \\
\hline & & $\mid \Delta F / G q$ & س & IDV/TG & $\mid f \wedge / \Delta G$ & $1 F V / \Delta 9$ & IG9/VT & \\
\hline$\cdot 1 \cdot \cdot 1$ & $\Lambda / \Delta V V$ & $11 / F V( \pm F / T V)$ & $11 / \Delta \varphi( \pm r / V \varphi)$ & $|r / q|( \pm F / r q)$ & $1 \cdot / f r( \pm f)$ & $1 \cdot / \Delta V( \pm F / V I)$ & $1 \cdot / \Lambda \vee( \pm r / \Delta 9)$ & محيط \\
\hline$\cdot 1 \cdot \cdot 1$ & $\mathrm{~V} / \cdot \mathrm{rt}$ & $r F / \cdot l\left( \pm \Delta / q^{\top}\right)$ & $r F / I V( \pm \Delta / \mathcal{F} \wedge)$ & $r F / \backslash \&( \pm \Delta / q T)$ & $T r / V \cdot( \pm \Delta)$ & $r T / K \cdot( \pm \Delta / \Delta V)$ & $r \& / V \cdot( \pm \Delta / r \Delta)$ & ابزار \\
\hline • & $F / 194$ & $r \varphi / T \cdot( \pm V / \Delta \varphi)$ & $\mathrm{r} \mathrm{\omega} / \Lambda \cdot( \pm \mathrm{V} / \mathrm{V} \mathrm{I})$ & $r \varepsilon / T \cdot( \pm V)$ & $r F / q \mid( \pm G / G r)$ & rF/AF $( \pm V / F I)$ & 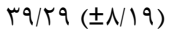 & وظايف \\
\hline$\cdot 1 \cdot+1$ & D//1/ & $\mid V / \& \varphi( \pm F)$ & IV/TG $( \pm F / V)$ & $\mid V / T \cdot( \pm r / T q)$ & 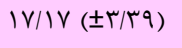 & $\mid V / \cdot q( \pm f / \mid I)$ & 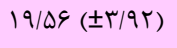 & فناورى \\
\hline$\cdot 1 \cdot 10$ & T/ITE & $\varphi \Delta / \mu^{\prime} \varphi( \pm \mid \varphi / \mu \wedge)$ & $G F / T \cdot( \pm \mid Q / \backslash \Lambda)$ & $\varepsilon \Delta / \vee q( \pm \mid F / \Gamma \Delta)$ & $G \mu / \mu F( \pm 1 \cdot \mid \Delta)$ & 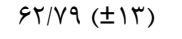 & $V \cdot / r \mid( \pm \mid V)$ & سازمان \\
\hline
\end{tabular}


جدول س. نتايج آزمون كاىدو براى مقايسٔ فراوانى دو گروه ماكروار گونومى برحسب اختلالات اسكلتى - عضلانى طى يك سال كذشته

\begin{tabular}{|c|c|c|c|c|c|c|}
\hline \multirow{2}{*}{$P$} & \multirow{2}{*}{ ميزان كاىدو } & \multicolumn{2}{|c|}{ ماكرواركونومى ** } & \multirow{2}{*}{ تروه } & \multirow{2}{*}{ نواحى بدن } & \multirow{2}{*}{ متغير } \\
\hline & & r & 1 & & & \\
\hline \multirow{2}{*}{$.1 \cdot \cdot 1$} & \multirow{2}{*}{$T V / T V$} & $\varepsilon r(r q / \mathcal{F})$ & $r T(\mid T / Y)$ & 1 & \multirow{2}{*}{ تردن } & \\
\hline & & $11 \cdot(\Phi / / 9)$ & $1 \Delta \Delta(\Lambda \vee / \varphi)$ & r & & \\
\hline \multirow{2}{*}{$\cdot 1 \cdot \cdot 1$} & \multirow{2}{*}{ FE/VV } & $11 \Delta(\& \& / \Delta)$ & $\Delta r(Y q / 9)$ & 1 & \multirow{2}{*}{ شانهها } & \\
\hline & & $\Delta \Lambda(\Psi r / \Delta)$ & ITF $(V \cdot / 1)$ & r & & \\
\hline \multirow{2}{*}{$.1 \cdot \cdot 1$} & \multirow{2}{*}{ rg/lF } & $109(91 / 9)$ & $119(9 \Delta / \Delta)$ & 1 & \multirow{2}{*}{ آرنجها } & \\
\hline & & $\operatorname{lf}(\Lambda / 1)$ & G) $(M / D / D)$ & r & & \\
\hline \multirow{2}{*}{$.1 \cdot .1$} & \multirow{2}{*}{99190} & $|r|(V \Delta / V)$ & $\Delta V(T r / T)$ & 1 & \multirow{2}{*}{ مج ودستها } & \\
\hline & & $\operatorname{Fr}(T F / T)$ & $\mid r \cdot(g V / A)$ & r & & اختلالات \\
\hline \multirow{2}{*}{$.1 \cdot \cdot 1$} & \multirow{2}{*}{$\wedge F / V \backslash$} & IrT $(V / /)$ & rq (Yr) & 1 & \multirow{2}{*}{ يشت } & اسكلتى -عضلانى \\
\hline & & $\Delta \cdot(\leftarrow \& / \Gamma)$ & IrA (VA) & r & & كذشته* \\
\hline \multirow{2}{*}{$\cdot 1 \cdot .1$} & \multirow{2}{*}{$G Y / F \mid$} & $\vee \wedge(F \Delta / 1)$ & If $(V / 9)$ & 1 & \multirow{2}{*}{ نشيمن و كمر } & \\
\hline & & $9 \Delta(\Delta F / 9)$ & IET (9T/1) & r & & \\
\hline \multirow{2}{*}{$\cdot 1 \cdot \cdot 1$} & \multirow{2}{*}{$|f| / f \mid$} & $191(94 / 1)$ & $110(9 \Delta)$ & 1 & \multirow{2}{*}{ يك يا هر دو ران } & \\
\hline & & Ir $(9 / 9)$ & GT (TQ) & r & & \\
\hline \multirow{2}{*}{$\cdot 1 \cdot \cdot 1$} & \multirow{2}{*}{$\Delta \Lambda / T \varphi$} & $\| f \wedge(\wedge \Delta / \Delta)$ & $\Lambda \Gamma(F \& / q)$ & 1 & \multirow{2}{*}{ يك يا هر دو زانو } & \\
\hline & & $r \Delta(\mid F / \Delta)$ & $q F(\Delta r / l)$ & r & & \\
\hline \multirow{2}{*}{$\cdot 1 \cdot \cdot 1$} & \multirow{2}{*}{$r V / T$} & $9 \Delta(\Delta F / 9)$ & $F)(T r / T)$ & 1 & \multirow{2}{*}{ يك يا هر دو پا } & \\
\hline & & $V \wedge(F \Delta / 1)$ & I I (V\&|A) & r & & \\
\hline
\end{tabular}

جدول F. نتايج آزمون كاىدو براى مقايسُٔ فراوانى دو كروه ماكروار كونومى برحسب استرس به تفكيك بيمارستانها

\begin{tabular}{|c|c|c|c|c|c|c|}
\hline \multirow[t]{2}{*}{$P$} & \multirow{2}{*}{ ميزان كاى دو } & \multicolumn{2}{|c|}{ ماكرواركونومى * * } & \multirow{2}{*}{ تروه } & \multirow{2}{*}{ بيمارستان } & \multirow{2}{*}{ متغير } \\
\hline & & r & 1 & & & \\
\hline \multirow{2}{*}{$.1 \cdot .1$} & \multirow{2}{*}{$r \mid / T$} & $F F(\Lambda r)$ & $F(T H / Q)$ & 1 & \multirow{2}{*}{1} & \\
\hline & & $9(I V)$ & $\mathbb{I r}(V \& \mid Q)$ & r & & \\
\hline \multirow{2}{*}{$.1 \cdot .1$} & \multirow{2}{*}{ TV/FF } & r (qT) & $\mathbb{I r}(r g / V)$ & 1 & \multirow{2}{*}{ r } & \\
\hline & & $r(\Lambda \Gamma)$ & س & r & & \\
\hline \multirow{2}{*}{$.1 \cdot .1$} & \multirow{2}{*}{$\mid N / G F$} & $\|(\boldsymbol{F} N / I)$ & $r(\boldsymbol{F} / \mathrm{V})$ & 1 & \multirow{2}{*}{ r } & \\
\hline & & $\mid f(\Delta \mid / 9)$ & f) $(q \Delta / r)$ & r & & \\
\hline \multirow{2}{*}{$.1 \cdot \cdot 1$} & \multirow{2}{*}{ TEIDT } & $r \Delta(1 \cdots)$ & $\|(\Gamma / / 4)$ & 1 & \multirow{2}{*}{ r } & استرس * \\
\hline & & $\cdot(\cdot)$ & TF $(\varepsilon \wedge / \varepsilon)$ & r & & \\
\hline \multirow{2}{*}{$\cdot 1 \cdot .1$} & \multirow{2}{*}{$r \& / 11$} & rq (^V/৭) & $1 \cdot(Y V)$ & 1 & \multirow{2}{*}{$\Delta$} & \\
\hline & & $F(\mid T / I)$ & TV (VT) & r & & \\
\hline \multirow{2}{*}{$.1 \cdot \cdot 1$} & \multirow{2}{*}{ ع } & $\operatorname{lfF}(\Lambda \mu / T)$ & $r q(T r)$ & 1 & \multirow{2}{*}{ كل } & \\
\hline & & rq (|\&/A) & $\mid r \wedge(\vee \wedge)$ & $r$ & & \\
\hline
\end{tabular}

ماكروارگونومى در بيمارستان 1 مطلوبتر و در بيمارستان ؟ و

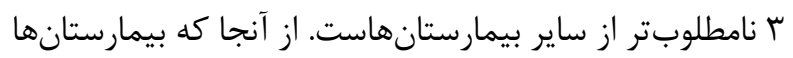

يافتههاى مطالعهُ حاضر نشان داد وضعيت ماكروارگونومى

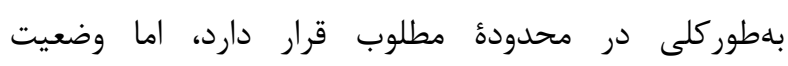




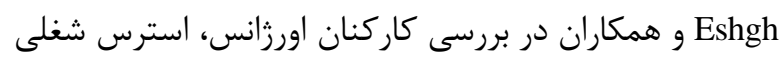

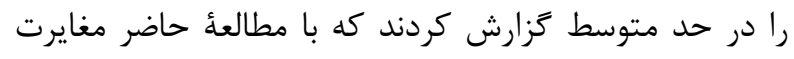

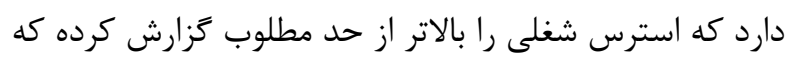

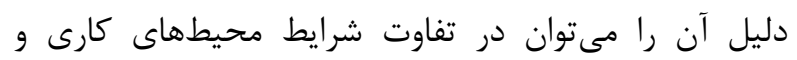

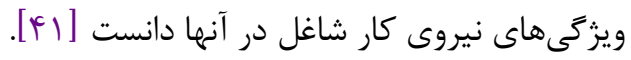

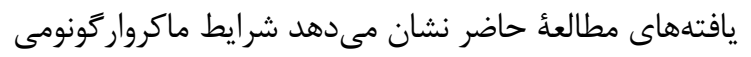

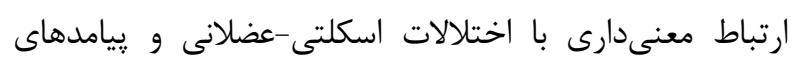

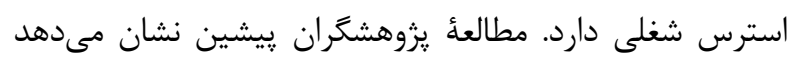

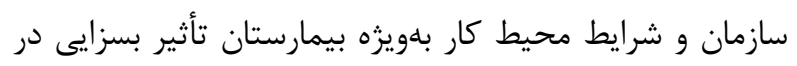

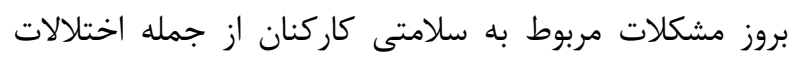

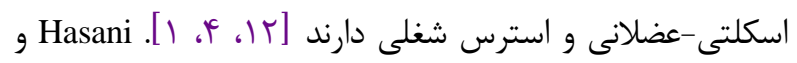

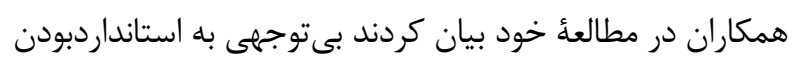

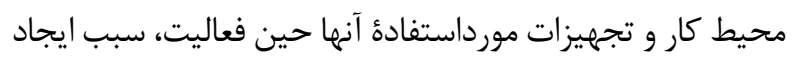

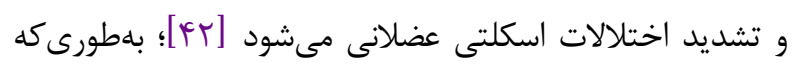

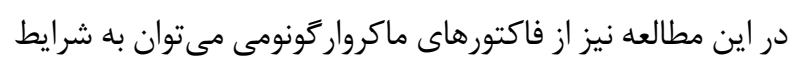

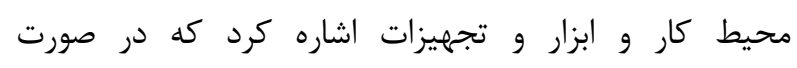
نامطلوببودن محيط كار و عدم تناسب ابزار و تجهيزات بار ابعات ابعاد بدن افراد شاغل موجب افزايش اختلالات اسكلتى-عضلانى در درد

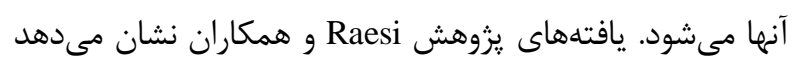

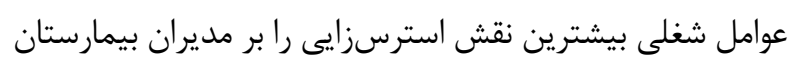

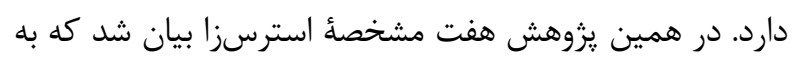

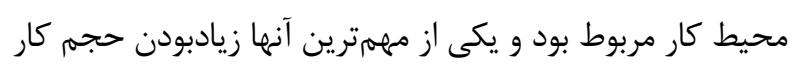

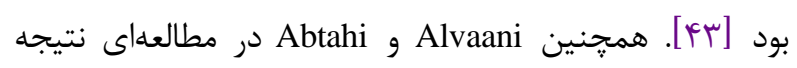

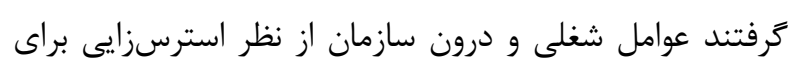

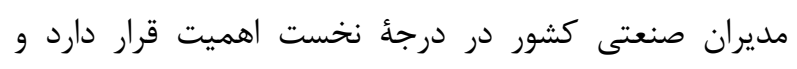

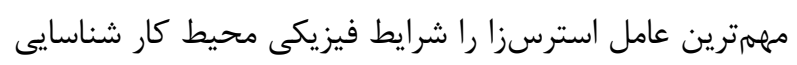

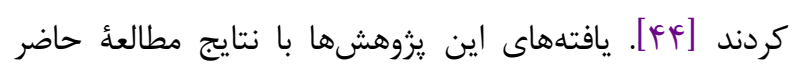

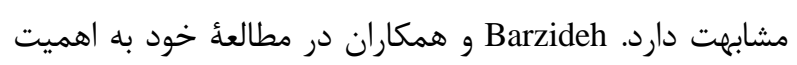

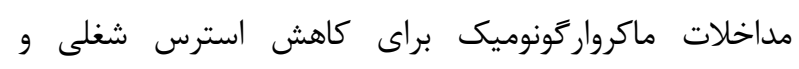

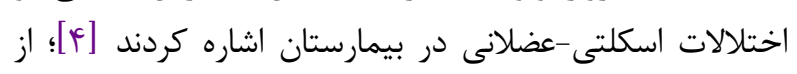

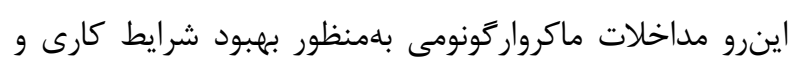

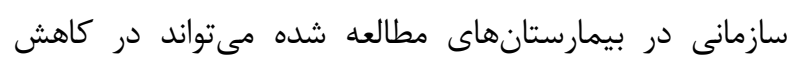
آسيبهاى اسكلتى-عضلانى و رِيامدهاى استرس شغلى مؤنى مؤثر باشد.

اين مطالعه با وجود برخى محدوديتها، اولين مطالعه در

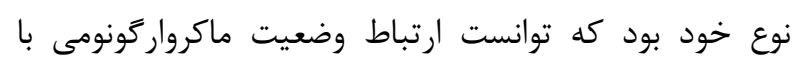

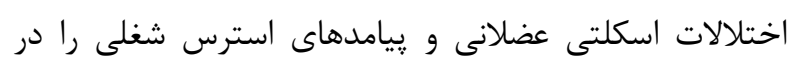

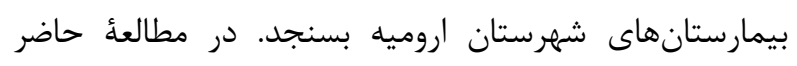

تيمهاى مديريتى متفاوتى براى مديريت امور بيمارستانى داشتند،

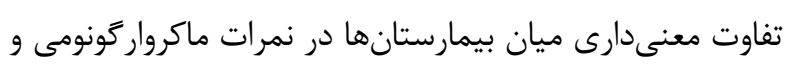

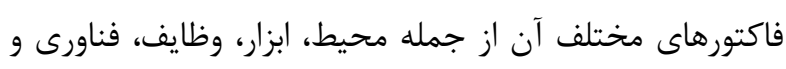

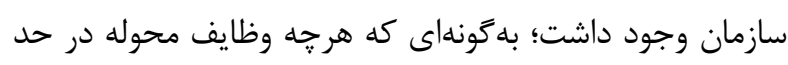

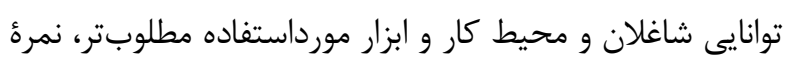

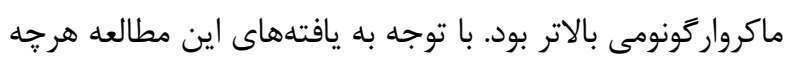

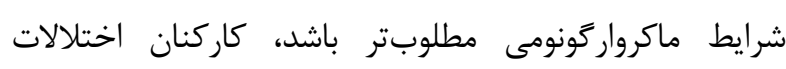

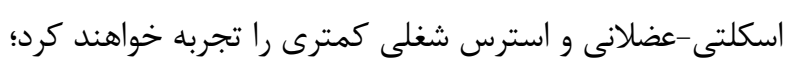

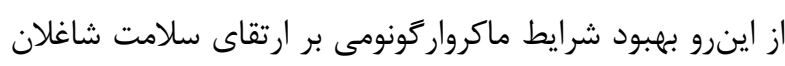

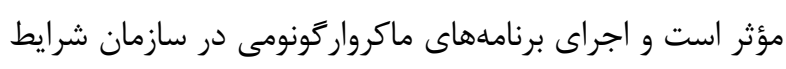

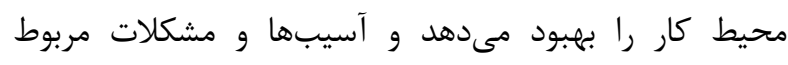

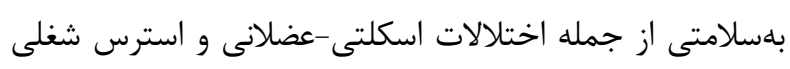

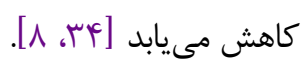
شيوع بالاى اختلالات اسكلتى-عضلانى در ميان كاركنان

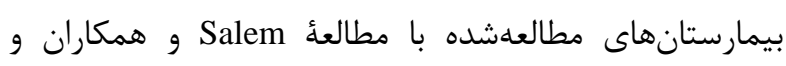
Ayatollahi

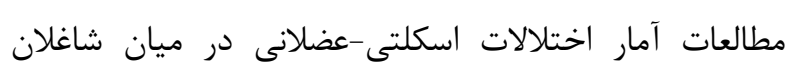

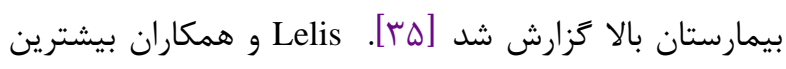

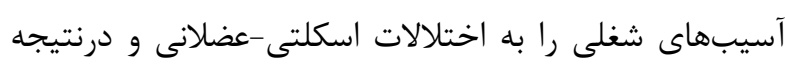

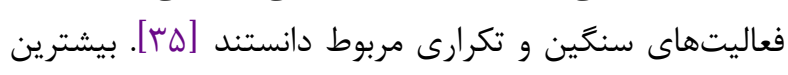

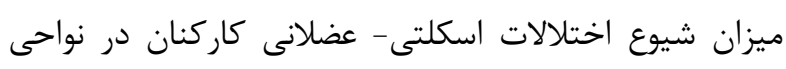

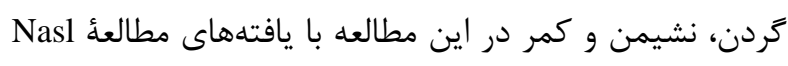
Saraji يافتهاى Abareshi و همكاران كه شيوع بارن بالاى دردهاى

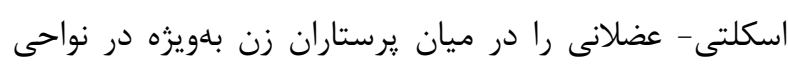

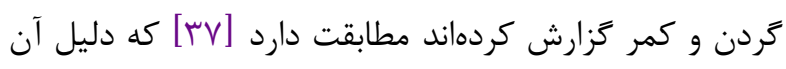

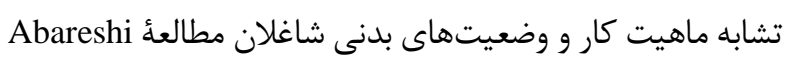

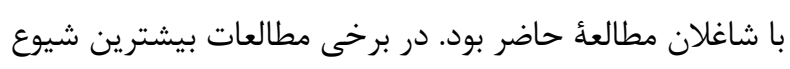

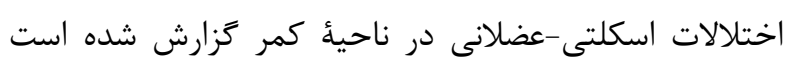

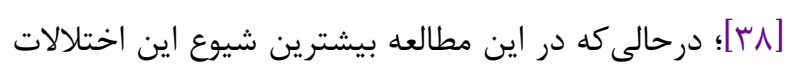

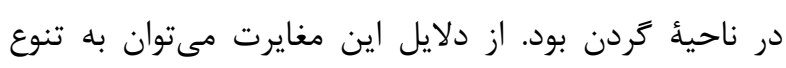

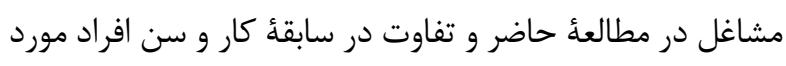
مطالعه اشاره كرد.

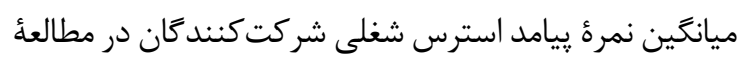

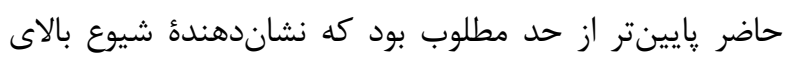

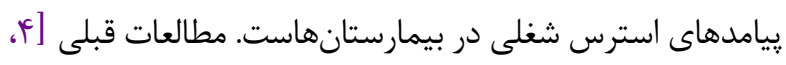

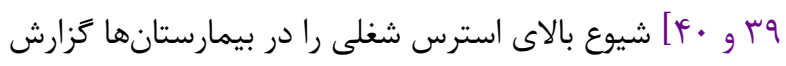

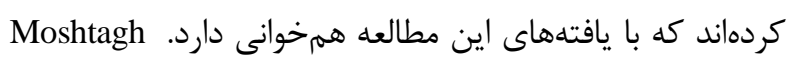




$$
\begin{aligned}
& \text { به ارتقا وضعيت ماكروار گونومى منجر شود و در كاهش آسيبهاى } \\
& \text { شغلى مؤثر باشد. } \\
& \text { تقدير و تشكر } \\
& \text { اين مقاله برَرفته از يايانامه نويسنده اول مقاله است. }
\end{aligned}
$$

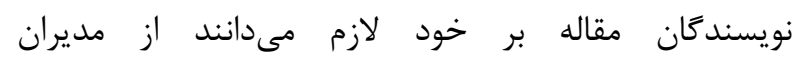

$$
\begin{aligned}
& \text { بيمارستانهاى آموزشى - درمانى و تمامى مشاركت كنند مان } \\
& \text { در اين مطالعه تشكر و قدردانى نمايند. } \\
& \text { كد كميته اخلاق }
\end{aligned}
$$

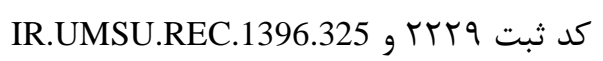

$$
\begin{aligned}
& \text { تعارض منافع } \\
& \text { بين نويسند } \\
& \text { منابع مالى } \\
& \text { اين مطالعه با حمايت مالى معاونت يزوهش، تحقيقات و فناورى } \\
& \text { دانشعاه علوم يزشكى اروميه انجام شده است. }
\end{aligned}
$$

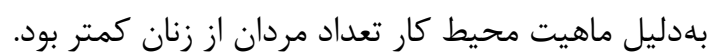

$$
\begin{aligned}
& \text { نتيجه گَيرى }
\end{aligned}
$$

\section{References}

1. García-Herrero S, Mariscal MA, García-Rodríguez J, Ritzel DO. Working conditions, psychological/physical symptoms and occupational accidents. Bayesian network models. Safety science. 2012 Nov 1;50(9):1760-74. [DOI:10.1016/j.ssci.2012.04.005]

2. Nahrgang JD, Morgeson FP, Hofmann DA. Safety at work: a meta-analytic investigation of the link between job demands, job resources, burnout, engagement, and safety outcomes. Journal of applied psychology. 2011 Jan;96(1):71. [DOI:10.1037/a0021484] [PMID]

3. Carayon P, Gürses AP. A human factors engineering conceptual framework of nursing workload and patient safety in intensive care units. Intensive and Critical Care Nursing. $2005 \quad$ Oct 1;21(5):284-301. [DOI:10.1016/j.iccn.2004.12.003] [PMID]

4. Barzideh M, Choobineh AR, Tabatabaee HR. Job stress dimensions and their relationship to musculoskeletal disorders in Iranian nurses. Work. 2014 Jan 1;47(4):423-9. [DOI:10.3233/WOR-121585] [PMID]

5. Abdollahpour N, Helali F, Peysepar S. An Improving Working Condition System (health, safety and ergonomics) Survey and analysis with Macroergonomics Approach in a manufacturing company from Iran Power Plant Industry in 2010. Iran Occupational Health. 2013 Nov 15;10(4):55-64.
6. Kleiner BM, Drury CG. Large-scale regional economic development: Macroergonomics in theory and practice. Human Factors and Ergonomics in Manufacturing \& Service Industries. 1999 Mar;9(2):151-63. https://doi.org/10.1002/(SICI)15206564(199921)9:2<151::AID-HFM2>3.0.CO;2-G [DOI:10.1002/(SICI)1520-6564(199921)9:23.0.CO;2-G]

7. Helali F, Shahnavaz H. Ergonomics intervention in industries of the industrially developing countries. Case study: Glucosan-Iran. Proceedings of Human Factors in Organizational Design and Management V. Amsterdam, The Netherlands: North-Holland. 1996:141-6.

8. Kleiner BM. Macroergonomics: analysis and design of work systems. Applied ergonomics. 2006 Jan 1;37(1):81-9. [DOI:10.1016/j.apergo.2005.07.006] [PMID]

9. Hanse JJ, Forsman M. Identification and analysis of approach employing video-computer interaction. Applied Ergonomics. 2001 Feb 1;32(1):23-9. [DOI:10.1016/S00036870(00)00057-0]

10. Halvani GH, Fallah H, Hokmabadi RA, Smaeili S, Dabiri R, Sanei B, Saberi A. Ergonomic assessment of work related musculoskeletal disorders risk in furnace brickyard workers in Yazd. Journal of North Khorasan University of Medical Sciences. 2014 Dec 10;6(3):543-50. [DOI:10.29252/jnkums.6.3.543] unsatisfactory psychosocial work situations: a participatory 
11. Lotfizadeh M, Noor-Hassim E, Habibi E. Analysis of occupational stress and the related issues among employees of Esfahan steel company (ESCO), Iran (2009). Journal of Shahrekord Uuniversity of Medical Sciences. 2011;13. (5):37-45.

12. Sherehiy B, Karwowski W. The relationship between work organization and workforce agility in small manufacturing enterprises. International Journal of Industrial Ergonomics. 2014 May 1;44(3):466-73. [DOI:10.1016/j.ergon.2014.01.002]

13. Ayatollahi J, Hatami H, Ghavidel F. Occupational health hazards among health care workers of Shahid Sadoughi Hospital. Iran Occupational Health. 2007 Apr 15;4(1):258.

14. Salem M, RashidiJahan H, Tavakoli R, Sanaienasab H, Pourtaghi G. Study of work related diseases among staff of a hospital in Tehran. Journal of North Khorasan University of Medical Sciences. 2014 Jun 10;6(1):71-9. [DOI:10.29252/jnkums.6.1.71]

15. Leigh JP, Markowitz SB, Fahs M, Shin C, Landrigan PJ. Occupational injury and illness in the United States: estimates of costs, morbidity, and mortality. Archives of Internal Medicine. 1997 Jul 28;157(14):1557-68. [DOI:10.1001/archinte.157.14.1557] [PMID]

16. Pransky G, Benjamin K, Hill-Fotouhi C, Himmelstein J, Fletcher KE, Katz JN, Johnson WG. Outcomes in workrelated upper extremity and low back injuries: Results of a retrospective study. American journal of industrial medicine. $2000 \quad$ Apr;37(4):400-9. https://doi.org/10.1002/(SICI)10970274(200004)37:4<400::AID-AJIM10>3.0.CO;2-C [DOI:10.1002/(SICI) 1097-0274(200004)37:43.0.CO;2-C]

17. Sadra Abarghouei N. Comprehensive ergonomic interventions for improving ergonomic conditions in an automobile spare part manufacturing plant: A case study. Iranian Journal of Ergonomics. 2015 Sep 15;3(2):1-3.

18. Carayon P, Smith MJ, Haims MC. Work organization, job stress, and work-related musculoskeletal disorders. Human factors. $1999 \quad$ Dec;41(4):644-63. [DOI:10.1518/001872099779656743] [PMID]

19. Nwaelele OD. Macroergonomics interventions: Influence of referralmethod, psychosocial, and demographic factors on outcomes. Seattle University; 2015.

20. Sadra Abarqhouei N, Hosseini Nasab H, Fakhrzad MB. Macro ergonomics interventions and their impact on productivity and reduction of musculoskeletal disorders: including a case study. Iran occupational health. 2012 Nov 15;9(2):27-39.

21. Kazemi M, Safari Sh, Akbari J, Mououdi M A, Mahaki B. Relative Stress Index (RSI): MacroErgonomics Risk Assessment of jobs in textile industry. J Health Syst Res 2014; 10(4):669-677.

22. Hendrick HW. An overview of macroergonomics. Macroergonomics: Theory, methods, and applications. 2002 Apr 1:1-23. [DOI:10.1201/b12477-2] [PMID]
23. Habibi E, Amini N, Porabdian S, Rismanchian M. Assessment of relationship between Macro Ergonomic conditions and employees work satisfaction Touse-eh and Omran factory. Iran Occupational Health. $2008 \mathrm{Apr}$ $15 ; 5(1): 15-20$.

24. Stanton NA, Hedge A, Brookhuis K, Salas E, Hendrick HW, editors. Handbook of human factors and ergonomics methods. CRC press; 2004 Aug 30. [DOI:10.1201/9780203489925]

25. Realyvásquez A, Maldonado-Macías AA, García-Alcaraz J, Cortés-Robles G, Blanco-Fernández J. Structural model for the effects of environmental elements on the psychological characteristics and performance of the employees of manufacturing systems. International journal of environmental research and public health. 2016 Jan;13(1):104. [DOI:10.3390/ijerph13010104] [PMID] [PMCID]

26. Morgeson FP, Humphrey SE. The Work Design Questionnaire (WDQ): developing and validating a comprehensive measure for assessing job design and the nature of work. Journal of applied psychology. 2006 Nov;91(6):1321. [DOI:10.1037/0021-9010.91.6.1321] [PMID]

27. Sims Jr HP, Szilagyi AD, Keller RT. The measurement of job characteristics. Academy of Management journal. 1976 Jun 1;19(2):195-212. [DOI:10.2307/255772] [PMID]

28. Campion MA. Interdisciplinary approaches to job design: A constructive replication with extensions. Journal of applied psychology. 1988 Aug;73(3):467. [DOI:10.1037/0021-9010.73.3.467]

29. Ostry AS, Marion SA, Demers PA, Hershler R, Kelly S, Teschke K, Hertzman C. Measuring psychosocial job strain with the job content questionnaire using experienced job evaluators. American journal of industrial medicine. 2001 Apr;39(4):397-401. [DOI:10.1002/ajim.1030] [PMID]

30. Choi B, Ko S, Ostergren PO. Validity test of the IPD-work consortium approach for creating comparable job strain groups between Job Content Questionnaire and demandcontrol questionnaire. International journal of occupational medicine and environmental health. 2015 Apr 1;28(2):32133. [DOI:10.13075/ijomeh.1896.00355] [PMID]

31. Dababneh A, Lowe B, Krieg E, Kong YK, Waters T. A checklist for the ergonomic evaluation of nonpowered hand tools. Journal of Occupational and Environmental Hygiene. 2004 Dec 1;1(12):D135-45. [DOI:10.1080/15459620490883150] [PMID]

32. Janowitz IL, Gillen M, Ryan G, Rempel D, Trupin L, Swig L, Mullen K, Rugulies R, Blanc PD. Measuring the physical demands of work in hospital settings: design and implementation of an ergonomics assessment. Applied ergonomics. $2006 \quad$ Sep 1;37(5):641-58. [DOI:10.1016/j.apergo.2005.08.004] [PMID]

33. Dickinson CE, Campion K, Foster AF, Newman SJ, O'rourke AM, Thomas PG. Questionnaire development: an examination of the Nordic Musculoskeletal Questionnaire. Applied ergonomics. 1992 Jun 1;23(3):197-201. [DOI:10.1016/0003-6870(92)90225-K] 
34. Hendrick HW, Kleiner BM. Macroergonomics: Theory, methods, and applications. Lawrence Erlbaum Associates Publishers; 2002. [DOI:10.1201/b12477]

35. Lelis CM, Battaus MR, Freitas FC, Rocha FL, Marziale MH, Robazzi ML. Distúrbios osteomusculares relacionados ao trabalho em profissionais de enfermagem: revisão integrativa da literatura. Acta paulista de enfermagem. 2012;25(3):477-82. [DOI:10.1590/S010321002012000300025]

36. Nasl Saraji J, Hosseini M, Shahtaheri S, Golbabaei F, Ghasemkhani M. Evaluation of ergonomic postures of dental professions by Rapid Entire Body Assessment (REBA), in Birjand, Iran. jdm. 2005; 18 (1):61-67.

37. Abareshi F, Hekmatshoar R, Rastaghi S, Sharifi Z. Appropriateness of Hospital Equipment Ergonomic Indices to Nurse's anthropometric Dimensions. Journal of Occupational Hygiene Engineering Volume. 2019 Jan 1;5(4):33-40. [DOI:10.29252/johe.5.4.33]

38. Showraki N, Fakhraei F, Saadatmand N, Farhadi A. Effects of Teaching Ergonomic Principles on Working Status in Dental Students. ISMJ. 2019 Jun 15;22(2):130-40. [DOI:10.29252/ismj.22.2.130]

39. Magnago TS, Lisboa MT, Griep RH, Kirchhof AL, Guido LD. Psychosocial aspects of work and musculoskeletal disorders in nursing workers. Revista latino-americana de enfermagem. $\quad 2010 \quad$ Jun;18(3):429-35. [DOI:10.1590/S0104-11692010000300019] [PMID]

40. Karasek R. Healthy work. Stress, productivity, and the reconstruction of working life. 1990.

41. Moshtagh Eshgh Z, Peyman A, Amirkhani A, Taghinejad F. The relationship between occupational stresses with job burnout in pre-hospital emergency staff. Jorjani Biomedicine Journal. 2014 Dec 10;2(2):41-33.

42. Hasani A, Mobaraki H, Moghadami Fard Z. The importance of ergonomics in increasing efficiency and improve the performance of employees of the Ministry of Health and Medical Education. Journal of Occupational Medicine specialized. 2013;4(4):92-101.

43. Raesi P. The effect of stress on the performance and efficiency of hospital managers and matrons. Journal of Health Administration. 2000 Apr 10;3(6):176-91.

44. Alvaani M, Abtahi H. Research on stress management in the country's industrial sector. Management Studies in Development and Evolution. Volume 2, Issue 5, Spring 1992, Page 12-40. 
تعدادى از يرسش هاى فاكتور هاى يرسشنامهُ ماكرواركونومى

شرايط محيطى من وظايف كارى خود را در محيطى با تراز شدت صداى مناسب انجام مىدهمه.

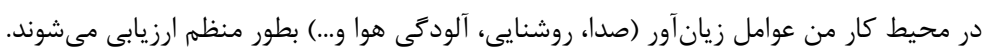
كاركنان از ابزارها بهطور نادرست استفاده مى كنند. آموزش كافى به كار كنان دربارة استفاده از ابزار داده شده است. وظايف شغل من نيازمند وظايف متنوعى است. اهداف، وظايف و فعاليتهاى شغلى من بسيار تخصصى است.

فناورى اين شغل به استفاده از تجهيزات يا فناورى بيجيده نياز دارد. استفاده از نمايشكرها و كنترلها در كنار هم امكان عكسالعمل آسان و راحت را فراهم كرده است.

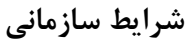

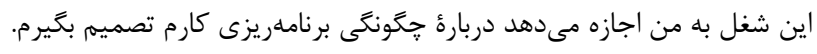
اين شغل براى فرد شاغل فرصتى فراهم مى كند تا توانايىهاى ويزئه خود را توسعه دهد.

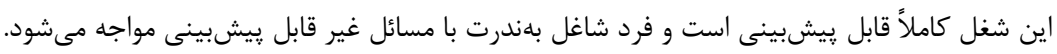
فرد شاغل وظايفى را انجام مىدهد كه به روشنى تعريف و مشخص شدهاند.

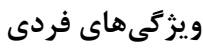

سن: سال ميزان تحصيلات: بىسواد، ابتدايى، راهنمايى، متوسطه و دانشكاهى 